\title{
A DESIGN OF AN AUTOMATED PARKING SYSTEM ON A SMART CAMPUS
}

\author{
Delaney Brown, Carson-Newman University, dhbrown@cn.edu \\ SeongYong Hong, Carson-Newman University, shong@cn.edu
}

\begin{abstract}
On the majority of college campuses, parking is frustrating for faculty, students and temporary guests. The issue with parking on college campuses is the amount of time spent finding a convenient parking space for their schedule that day. Students and faculty must spend time finding just a single open spot. The spot may be on the other side of campus if the parking is busy for that time of day. Assigned spaces are not ideal because students and staff can have classes or meetings in different buildings on campus. This paper will present the idea of design of an automated parking system specifically for college campus use. With this system in place faculty and students will be able to reserve their parking space prior to arriving on campus and confirm their space by simply scanning a Quick Response code (QR code) once they have parked in their chosen space. The purpose of this proposed idea is to create a system that will be beneficial to all guests on campus, as well as the environment, by eliminating extra trips around campus trying to locate an available parking space.
\end{abstract}

Keywords: Automated Parking System (APS), Smart Parking, Quick Response Code (QR Code)

\section{INTRODUCTION}

The Internet of Things can be defined as every day, ordinary objects having the ability to connect to the internet, allowing remote control or monitoring of such objects. If an object is described as "smart", it has the ability to connect to a network and interact within that network to make something more efficient. In largely populated big cities, there have been implementations of Smart Parking or Automating Parking Systems to make parking more convenient and less time consuming. There are many different branches of these parking systems. For example, there are Smart Garages that display available spots upon entering the garage. There are applications that can be downloaded to find available parking based on current location, and many other variations that can be very helpful. College campuses are an excellent area for the automated parking system. Students and faculty all have to be at the same place during the same times in a day. With classes having a set schedule, parking becomes a hassle on the daily basis. Sometimes students and even faculty can be late to their specific classes just because they spend too much time trying to find a parking spot. Time is very valuable to college students and faculty, so by decreasing parking time and hassle we can take away some of the stress that students face on the daily basis. The purpose of this research is to describe the design of an Automated Parking System on a college campus, making it a Smart Campus. The major components of an Automated Parking System include software for reserving a parking spot, software for security offices to monitor parking, a database to store data of drivers, and scannable QR codes located at each parking spot. The software for students and staff would be developed into an application in which the user inputs their schedule. The schedule is then saved in Google Firebase, which is a database, under the student or faculty ID number and accessed whenever the student or staff member wants to reserve a parking spot. When the user chooses to reserve a parking spot, the application will access the information in Google Firebase to provide the most optimal available parking spaces based on the users previously uploaded schedule. The user is presented with the available parking spots in the most ideal parking lot from which they can choose a spot to reserve. When they choose which spot, they would like to reserve, it deducts the cost of parking from their account balance and saves data used to confirm the correct spot when the driver arrives. Each parking spot should have a QR code printed on a post near the driver side of the vehicle. When the driver parks, they open the parking application and scan the QR code for their reserved parking spot. The application evaluates the QR code that has been scanned and compares it to the information saved when the spot was reserved. If the data matches, the user is given a message indicating they are in the correct parking spot. If the data does not match, the driver will be informed the parking spot is unavailable and will be instructed to relocate. If someone approaches their reserved parking spot and it is occupied by another vehicle, they will have the option to report "someone is in my spot" and will be assigned the closest available parking spot at no cost and will be refunded. 


\section{Issues in Information Systems}

Volume 20, Issue 2, pp. 29-37, 2019

There will be a more detailed description of this later in the paper. The software that will be available to security offices, allows them to access who has reserved each parking spot. They will also be notified if there is a vehicle in the incorrect parking spot. The software development and implementation of the design have not yet been completed, but with further research and development should soon be possible.

\section{LITERATURE REVIEW}

There is plenty of research being done revolving APS and the technology required to make them successful. There are different categories of smart parking that branch into sectors like fully automated parking garages, reservation-based garages or parking lots, and guided parking facilities. Reservation based parking systems allows drivers to reserve their spot prior to their arrival via smart phone. Idris, Leng, Tamil, Noor and Razak (2009) looked at the implementations of many different APS and found that the efficiency of these systems is "undeniable". They also noted that E-parking allows users to check the availability before arriving to a parking area and sometimes offer the option to reserve a parking spot prior to their arrival. To make E-parking more efficient, payment can be tied into the reservation of the parking spot via the user's mobile device or the internet (Idris et al, 2009). In a separate implementation, Jog, Sajeev, Vidwans and Mallick (2015) describe how QR codes are sent to users as a form of confirming the identity of the driver once they arrive to their parking space. Yan et al (2010) presented CrowdPark; a reservation-based parking system that allows users to buy and sell their parking spaces. If someone is leaving their parking spot, they can sell it to someone who needs a parking spot. This is all done through a mobile application. Some of the challenges they faced were ensuring that users were being honest and not trying to work the system in their favor, locating the exact parking spot in question and handling flexible arrival and departure times of users (Yan et al, 2010). Incentives are used in order to encourage honesty from those using the system. If a buyer lies about not being able to access their spot, then they cannot resell it. SpotCheck and ActCheck are security checks that have been put in place in order to ensure honesty from the seller (Yan et al, 2010). Patil and Sakore (2014) implemented a parking system based on reservation and faced the challenges of fake parking requests, user's identity verification, delay in parking and a timer. They used a queue buffer which checked for multiple use of one user ID and would not allow a reservation to be made if the user ID had already been used to reserve a parking spot. To verify identity of the user, they use a QR code at the time of arrival. They implemented a timer in order to notify the user that their parking time was almost up and if the user is in the allocated parking spot longer then they are supposed to be, they will be charged for extra time (Patil \& Sakore, 2014). They concluded that this parking reservation system would be efficient in reducing amount of traffic searching for parking (Patil \& Sakore, 2014). Wang (2011) introduces a reservation-based parking system with the use of dynamic pricing. One of the challenges he faced is being able to satisfy the many drivers relying on this system. He does this by implementing a dynamic pricing system to meet the requests of different users. He also includes that most research is being done on the system design itself, including sensors that detect parking spot vacancy, but that his research includes pricing information which is effective in managing parking lots (Wang, 2011). The results of his research and simulation study find that a parking system based on reservation is able to accommodate users with varying needs and reduces traffic congestion and traffic searching for parking (Wang, 2011). Geng \& Cassandras (2012) implemented a "smart parking" system on the campus of Boston University, however, their conclusion states a "pilot program has been carried out in a garage at Boston University", but the results of that pilot are not disclosed (Geng \& Cassandras, 2012). In their implementation they use an LED light to indicate what the status of a parking spot is. Green for vacant, red for reserved, yellow for when the driver is approaching, and flashing red when the current parked vehicle is in the wrong spot. If the driver who is in the spot reserved by someone else does not leave within the allotted time frame, he is issued a fine and the driver who has reserved the spot will be assigned another spot (Geng \& Cassandras, 2012). With the findings of these previous studies, it is possible that the same results could come from implementing a reservation-based parking system designed specifically for a college campus. 


\section{RESEARCH METHODOLOGY}

UCLA spent $\$ 50$ million on more parking spaces in 2005, yet still the supply did not meet the demand (Shoup, 2006). The solution is not necessarily building more parking spaces but optimizing the spaces that are already established. Most campuses don't have the physical space or budget to build new parking spots or parking garages. An automated system could eliminate the need to create additional parking spaces on campus. Management and time spent by cars in the spaces is essential in maintaining the balance of college parking. During this day and age, technology is readily available and for the most part every person has access to the technological world. Majority of college campuses have Wi-Fi available to all student and faculty. The university already provides internet to those that need it which means that there would not be any exclusions by using the internet to help implement the automated parking system. Faculty and students often visit the internet for a multitude of reasons throughout their day. Since they are visiting the internet already, reserving a parking spot via the internet has potential. This thesis describes an Automatic Parking System that allows faculty and students to reserve a parking spot before arriving on campus. Based on the finding from Wang (2011) and Patil \& Sakore (2014), this will decrease the time and frustration spent searching for an available parking space. The parking spots that faculty and students can choose to reserve will be based on their schedule for the day. For example, if a student has a 9:00 a.m. class and a 12:00 p.m. class that are on opposite sides of the campus, the student will be shown the parking spaces available in the parking lot most convenient to the 9:00 a.m. class. The student will then be presented the most appropriate parking lot for the 12:00 p.m. class. Once the student or faculty member reserves their desired parking space, they will receive a confirmation message. When the driver arrives on campus, they can scan the QR Code in the front of their spot, to confirm they are in the spot they previously reserved. A further explanation of the software component of this project will be explained later in the paper.

\section{Contributions}

This paper projects an Automated Parking System implemented on a college campus, creating a Smart Campus. The implementation of this idea on a college campus would help regulate and optimize parking availability without having to create more parking spaces. The APS would include a reservation-based system for students and faculty to access from their mobile devices. It would also include software that security offices can use to help regulate parking. The APS makes it easier for student and faculty to park upon arrival and makes it easier for security to determine if someone parked in a space that they did not reserve. There will be a more detailed explanation of each software component later in the paper.

\section{Materials}

In order for this system to be successfully implemented, the only "hardware" needed would be the QR code posted in front of the parking spot on either a metal sign or plastic post along with a label, identifying the parking spot. The other portion of the system is the software, which can be deployed to mobile devices. There has not been a price set on the software, and the price of the hardware would be seemingly low considering what materials are needed. The Universities that wished to implement this system would be responsible for the costs. The application needs to be created for both iOS and Android operating systems to provide the same services to all students and faculty. Due to time constraint, only the Android application has begun development. For full implementation, both iOS and Android applications need to be fully developed in order to include users with differing mobile devices.

\section{Survey Results}

A survey was conducted in order to get feedback from a college student population by spreading the link to the survey via social media. The survey was created in Google Forums and was set up with multiple choice questions regarding Automatic Parking Systems. From April $9^{\text {th }}$ to June $19^{\text {th }}$, the survey was fully completed by thirty-eight people. The survey results will either support or deny the need for a Smart Campus on similar college campuses around the nation. The survey will convey results on issues like the attitudes toward the current parking system and the desire for a better parking system. The following tables represent the results from the survey conducted with college aged students on a small, private college campus. 


\title{
Trying to park on campus is frustrating and time consuming
}

\author{
38 responses
}

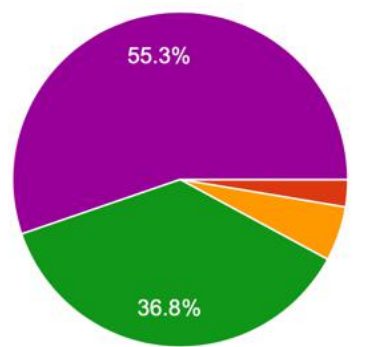

Strongly disagree

Disagree

Neutral

Agree

Strongly agree

Figure 1. Results of Parking Frustration and Time-Consuming Analysis

Figure 1 shows that ninety-percent of students either agree or strongly agree that trying to park on campus is frustrating and time consuming, while six percent remain neutral and three percent disagree. This shows a need to improve parking situations on college campuses.

\section{Parking would be easier if I knew where I was going to park before I got to campus \\ 38 responses}

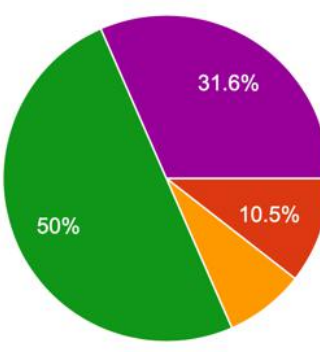

\author{
Strongly disagree \\ Disagree \\ Neutral \\ Agree \\ Strongly agree
}

Figure 2. Results of Knowledge of Parking Spot Prior to Arrival

Figure 2 displays the evidence that roughly eighty percent of students agree or strongly agree that parking would be easier if they knew where they were going to park before arriving on campus. This justifies the need for a reservationbased parking system. Figure 3 presents that only approximately sixteen percent of students are opposed to reserving their parking spot prior to reaching their destination. The other responses mainly supported the idea of reserving a parking spot, while a small percentage remained neutral on the topic. Reservation seems to be the most efficient way to fix the parking problems on campus. By reserving ahead of time, students will minimize time spent and possibly not securing a spot. First come first serve parking spots are not the most efficient use of time. 


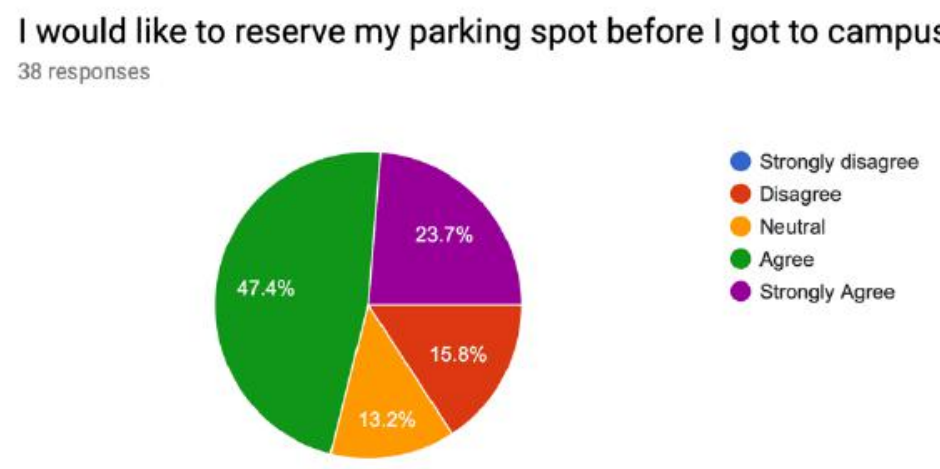

Figure 3. Feedback Around Parking Reservation

\section{Payment Method}

There were several payment methods that could be implemented with a parking reservation system. Wang (2011) describes a dynamic pricing system that changes the pricing on parking spaces based on the location of the parking spot. This way those who do not want to spend as much on parking, have an option to park farther away and pay less. CrowdPark has a payment system that utilizes "virtual credits" to encourage users to buy and sell their parking spaces (Yan et al, 2010). Pfizer uses a payment credit system in which their employees can park free every day, but if they decide not to drive, they receive a credit (about $\$ 3.50$ a day) to their account, then at the end of each month, the credits are added to their monthly pay (Shoup, 2006). This system encourages carpool, biking, walking, or other methods of transportation, which in turn frees up parking spaces on a daily basis for those who wish to drive to work. In regards to using this method on a college campus, "Some professors argue that charging for parking discourages coming to campus, while free parking encourages the faculty to make themselves available to meet with students, attend committee meetings and participate fully in the life of the university" (Shoup, 2006). With these methods in mind, payments could be set up similar to the way meal plans are managed on campus. Students pay a certain amount for a set number of meals in a cafeteria as well as dining dollars that can be spent at dining locations other than the cafeteria. The parking payment resembles this system such that students would pay a certain amount for the parking spot they reserved, but only the days they park on campus. These "parking dollars" would be included with "dining dollars". This would allow students to choose to spend their "University dollars" on parking or a fun meal outside of the cafeteria. Parking spaces that have a further walking distance would cost less than those that are closest to the building. This payment system would benefit both the students because they only pay for the parking they use and the University because it would motivate students who want to save their University dollars for meals instead of a parking spot. Also, by having pre-bought parking dollars, students and faculty do not have to carry cash or card to pay for parking. The payment will automatically go through at the time of reservation, eliminating the wait for approved payment. By having an online payment option, there will also eliminate staff as parking attendants.

\section{Application for Android}

The application for this project has been started in Android Studio using Java. The application has many responsibilities such as collecting student and faculty schedules and relaying them to a database. The app will also use the database to discover what parking spot best suites the user. It can keep track of what parking spots are occupied and displaying available spots to other users. The application uses Google Firebase to keep track of user login information and user's schedules. The application will prompt a user to enter their user ID. Once the user ID has been entered, it will compare it to the list of entries already in the database to ensure there are not duplicate entries. If the user has never used the application before, it will ask them to enter their class schedule to save for the next time they $\log$ in to reserve a parking spot. To make the process even more accurate, users can be asked if the application has permission to access their calendar in their device. Using this information students and teachers can put in meetings, events, etc., that are outside of their regular class schedule, but still have the option to reserve parking spots based off of the events in their calendar. It will also ask for their license plate number for identification purposes. Once the information is entered, the application will be able to see their schedule for the day and provide them with the available 
parking spots most convenient to their schedule based on the time and day of the week. Once they choose which parking spot they would like to reserve, they confirm in the application. When they arrive to the parking spot, they open the application and scan the QR code that is posted in front of their parking spot. If they are in the right parking spot, they will get a confirmation message telling them the amount that has been deducted from their account. If they park in the wrong parking spot, they will get a message stating they are in the incorrect parking space and need to relocate to the correct space or will be fined and possibly towed.
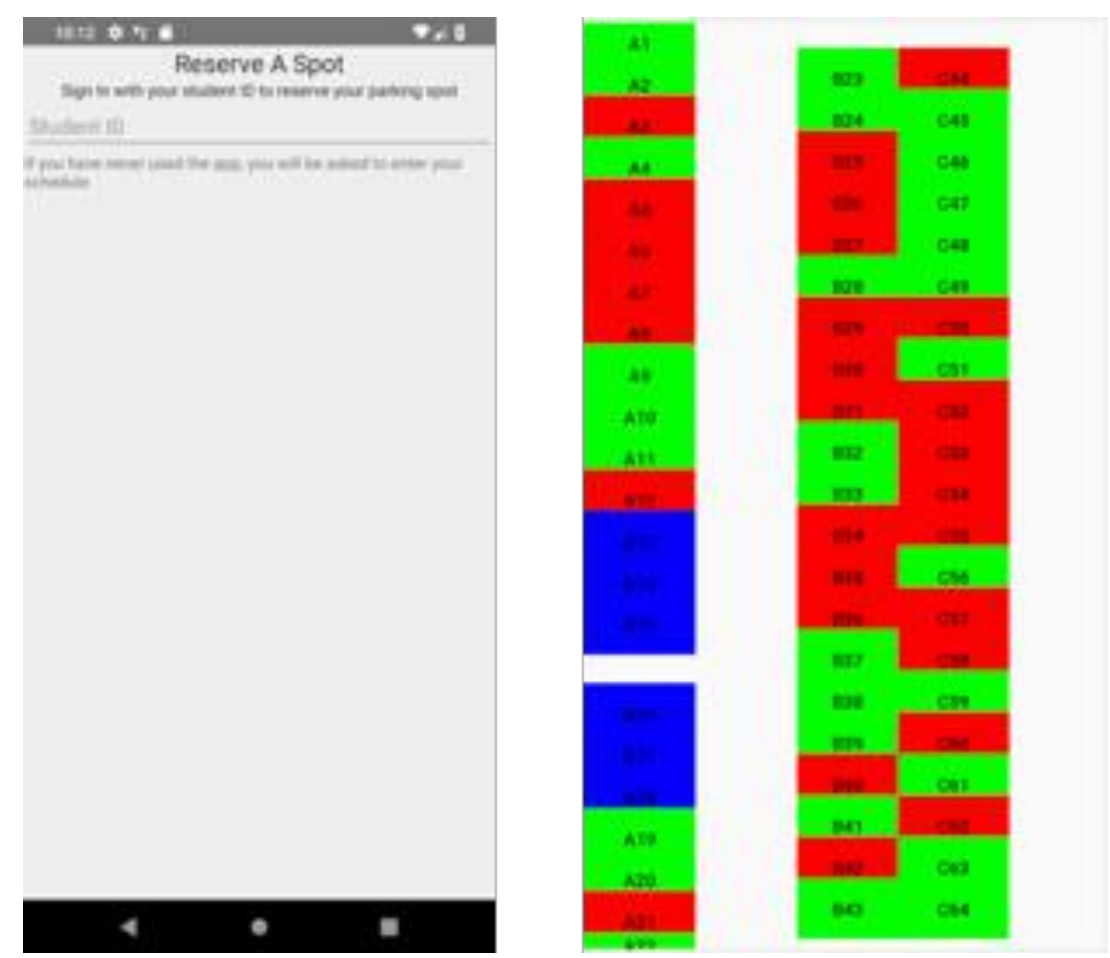

Figure 4. Mobile Application

Figure 4 shows the layout of the mobile application. The first image shows the opening page of the app that gathers the student ID. From this page, the algorithm checks the database until the student ID is found to see which parking lot is most convenient for the student driving. If the student has never added their schedule through the application, the program directs them to a new page where they select which buildings they will be in for each day of the week. If the student has previously input their schedule, then they are directed to a page similar to one on the right. This example shows the science building parking lot where green represents available spots, red represents unavailable and blue represents handicap spots. Once the user selects their spot from the above image, they will be provided with a confirmation message. 


\section{Issues in Information Systems}

Volume 20, Issue 2, pp. 29-37, 2019

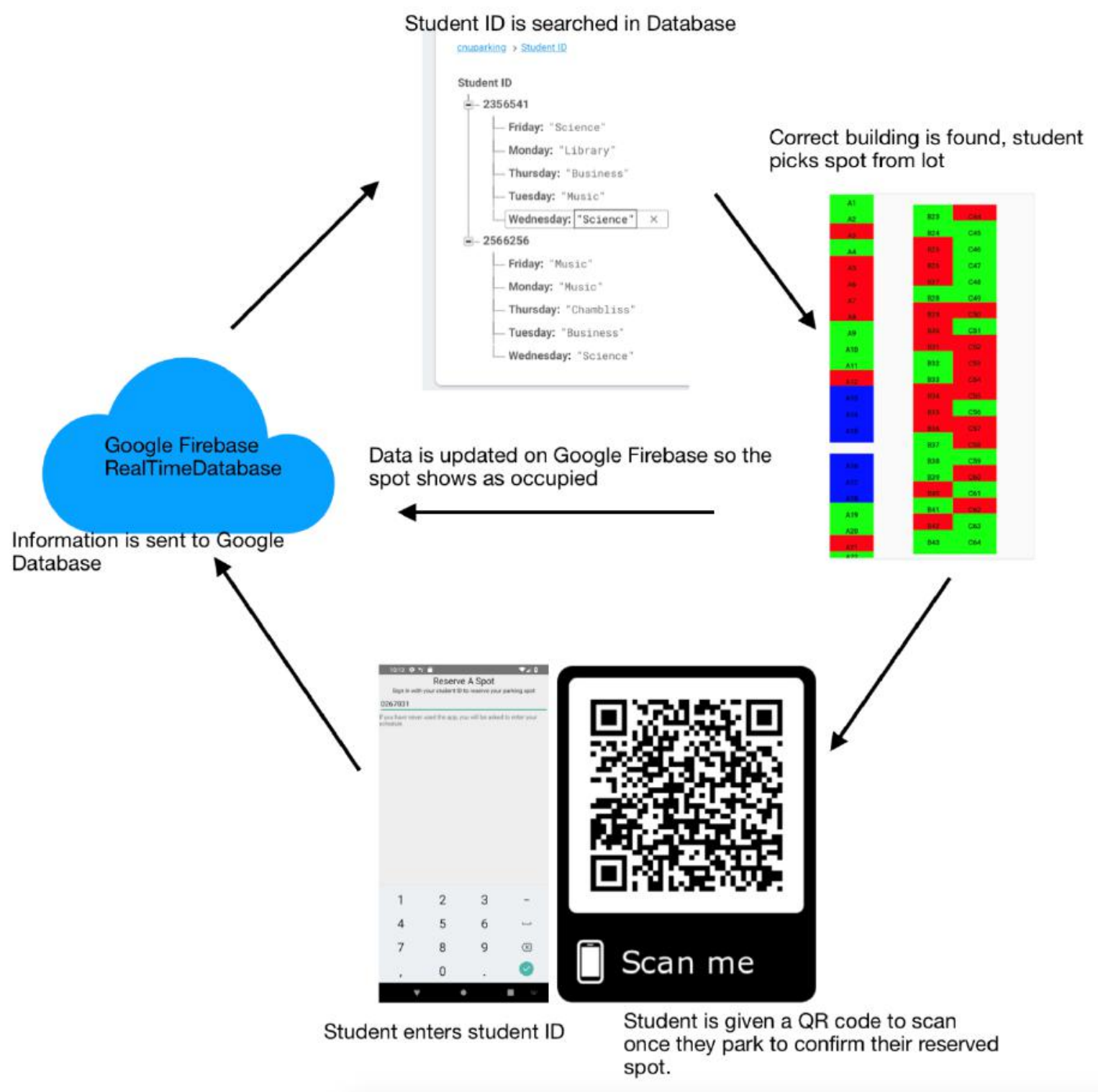

Figure 5. Architecture of Automated Parking System

Figure 5 displays the way the application interacts with the student and Google Firebase. The student enters their student ID which is then sent to Google Firebase. The database is then searched for the student ID. Once it is found, the student is shown an image of the parking lot which best suites their schedule. The green spots represent available and the red spots represent unavailable and blue represents handicap parking spaces. Once the student selects their spot, they are given a QR code to scan upon arrival. This will display a message about the parking spot. The QR codes in Figure 6 are examples of the feedback students may receive when scanning their QR code. 


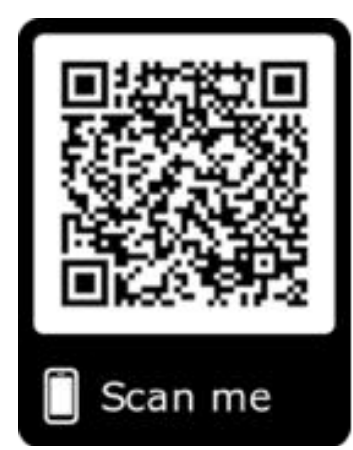

(a) Feedback for Incorrect Spot

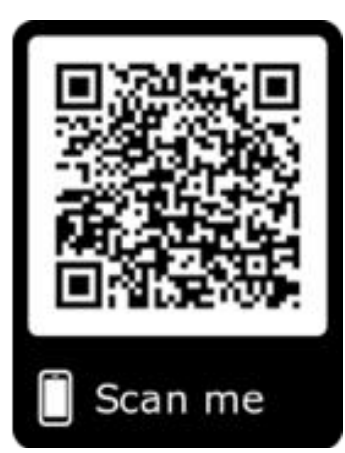

(b) Feedback for Correct Spot

\section{Human error}

Figure 6. Examples of QR Codes

If a user approaches their spot to find the spot being occupied by someone else, the application will have an option for them to report "someone is in my spot". They will need to take a picture of the car in the parking space to ensure they are not trying to scam the system. After the occupied spot has been reported, the application will automatically reserve the closest available parking space and apologize for the inconvenience. The picture that they took to report that someone was in their spot, is sent to be reviewed by the security office on site. Once it is confirmed that it is in fact someone else parked in the previously reserved parking spot, the user will be issued a refund. The license plate should be in the picture and if it has been used in the application before, they can be fined directly from the application. If they have not registered with the application, security can quickly find the parking spot and manually fine the person who has parked in the incorrect spot.

\section{RESULTS}

Once this system is implemented the expected results would be a positive impact on the students and the University. By implementing this system, it will save students time and the University would not have to employ someone closely monitoring parking lots. This would even have a positive impact on the environment by eliminating the amount of time the students spend driving their cars around looking for an available parking spot. By allowing students to reserve their parking spot before arriving on campus, there will be less frustration and time consumed searching for a parking spot.

\section{CONCLUSION}

After investigating and researching more into the automated parking system, we can see that the APS will provide benefits to college campuses across the nation. College campuses all have different issues; however, parking seems to be a common issue no matter the campus. Small campuses and large campuses spend each year trying to combat the issue of parking. Colleges spend money on having officers to enforce the system and must be able to provide a spot to all students that purchase a parking pass. There is then the issue of students not being able to buy a parking pass because of them being sold out. The automated parking system uses efficiency and management to reduce the stress and frustration that comes with parking. Not only will the students and faculty benefit from the parking system, but the college will benefit financially from it as well. This study was very limited due to the fact that it was not physically able to be tested. This is a very preliminary study and will allow for a lot of further study and implementation. In the future, simulators can be built with the parking system. Further surveys and population studies can also be conducted to see where the automated parking systems will best be utilized. The research can only be expanded from here and hopefully be used in college campuses across the nation in the future. The study also had some shortcomings. There was a limited size of students that were surveyed, and the survey was only conducted on a single campus. The survey could be more in depth for the future and be conducted on campuses across the nation. It can be assumed that most college campuses have the same parking issues, however, there needs to be a more in-depth knowledge on the specific issues that each campus faces. This specific automated parking system has potential to become a universal system that is popular among campuses. It can become a common name that most students and faculty know when it is referred 


\section{Issues in Information Systems}

Volume 20, Issue 2, pp. 29-37, 2019

to. To continue, a larger population size should be used in the future in order to eliminate outliers and to get a better presentation of the entire college student and faculty population.

This research contributes ideas that can make a smart parking system successful and beneficial to drivers and the University who implements it. Compared to the other implementations of similar studies, there are similarities and differences. Wang (2011) and Patil and Sakore (2014), both describe a reservation-based parking system, Patil \& Sakore (2014) use QR codes as a form of user identification, Shoup (2006) describes a similar payment system used by Pfsizer. but the most beneficial difference is that this APS utilizes the schedules of student and faculty in order to provide the best options for users. The research also lays a foundation that can be further developed and tested with more time and resources.

\section{ACKNOWLEDGMENTS}

We gratefully thank the Carson-Newman mathematics and physics department faculty for computer science capstone project advising and support.

\section{REFERENCES}

Idris, M., Leng, Y., Tamil, E., Noor, N., \& Razak, Z. (2009). Car Park System: A Review of Smart Parking System and Its Technology, Information Technology Journal, 8(2), 101-111.

Patil, M., \& Sakore, R. (2014). Smart Parking System Based on Reservation. International Journal of Scientific \& Engineering Research, 2(6), 21-26.

Prof. Jog, Y., Sajeev, A., Vidwans, S., \& Mallick, C.. (2015). Understanding Smart and Automated Parking Technology. International Journal of $u$ - and e-Service, Science and Technology, 8 (2), 251-262.

Shoup, D. (2006). Parking On A Smart Campus, California Policy Options 2005, Los Angeles: UCLA School of Public Affairs, 117-149.

Wang, H. (2011). A Reservation-based Smart Parking System, University of Nebraska-Lincoln, Computer Science and Engineering: Theses, Dissertations, and Student Research, 62.

Yan, T., Hoh, B., Ganesan, D., Tracton, K., Iwuchukwu, T., \& Lee, J. (2010). CrowdPark : A Crowdsourcing-based Parking Reservation System for Mobile Phones.

Yanfeng, G., Cassandras C. G. (2012). A new "Smart Parking” System Infrastructure and Implementation, Procedia - Social and Behavioral Sciences, 54, 1278-1287. 